\title{
Article
}

\section{Thermal characteristics of externally venting flames and their effect on the exposed façade surface}

Asimakopoulou, Eleni, Kolaitis, Dionysios and Founti, Maria

Available at http://clok.uclan.ac.uk/31934/

Asimakopoulou, Eleni ORCID: 0000-0001-5644-1372, Kolaitis, Dionysios and Founti, Maria (2017) Thermal characteristics of externally venting flames and their effect on the exposed façade surface. Fire Safety Journal, 91 . pp. 451460. ISSN 0379-7112

It is advisable to refer to the publisher's version if you intend to cite from the work. http://dx.doi.org/10.1016/j.firesaf.2017.03.075

For more information about UCLan's research in this area go to http://www.uclan.ac.uk/researchgroups/ and search for <name of research Group>.

For information about Research generally at UCLan please go to http://www.uclan.ac.uk/research/

All outputs in CLoK are protected by Intellectual Property Rights law, including Copyright law. Copyright, IPR and Moral Rights for the works on this site are retained by the individual authors and/or other copyright owners. Terms and conditions for use of this material are defined in the policies page.

\section{CLoK}

Central Lancashire online Knowledge www.clok.uclan.ac.uk

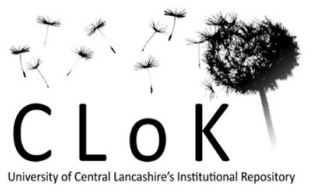




\title{
Thermal Characteristics of Externally Venting Flames and their Effect on the Exposed Façade Surface
}

\author{
ELENI K. ASIMAKOPOULOU, DIONYSIOS I. KOLAITIS* and MARIA A. FOUNTI \\ Laboratory of Heterogeneous Mixtures and Combustion Systems, \\ School of Mechanical Engineering, National Technical University of Athens, \\ 9 Heroon Polytechneiou St., Polytechneioupoli Zografou, Athens 15780, Greece \\ *e-mail: dkol@central.ntua.gr
}

\begin{abstract}
In a compartment fire, Externally Venting Flames (EVF) may significantly increase the risk of fire spreading to adjacent floors or buildings, especially when combustible insulation materials are installed on the building façade. An increasing number of recent reports suggest that existing fire engineering design methodologies cannot describe with sufficient accuracy the characteristics of EVF under realistic fire load conditions. In this context, a series of fire safety engineering design correlations used to describe the main EVF thermal characteristics, namely EVF centreline temperature and EVF-induced heat flux on the exposed façade surface, are comparatively assessed. Towards this end, measurements obtained in a medium- and a large-scale compartment-façade fire test are employed; aiming to broaden the scope of the validation study, predictions of the investigated correlations are further compared to measurements obtained in 6 large-scale fire tests found in the literature. It is found that the correlation proposed in EN1991-1-2 (Eurocode 1) for the estimation of the EVF centreline temperature is under-predicting the measured values in large-scale fire tests. In addition, it is concluded that estimation of the local flame emissivity should take into account the specific fuel type used in each case.
\end{abstract}

KEYWORDS: compartment fires; heat transfer; externally venting flames; façade fires; Eurocode.

\section{NOMENCLATURE LISTING}

\begin{tabular}{|c|c|c|c|}
\hline$A_{o}$ & Opening area $\left(\mathrm{m}^{2}\right)$ & $T_{z}$ & $\begin{array}{l}\text { EVF centreline temperature, related to the } \\
\text { height from the opening lintel }(\mathrm{K})\end{array}$ \\
\hline$A_{v}$ & Area of vertical openings $\left(\mathrm{m}^{2}\right)$ & $T_{\text {wall }}$ & Wall temperature $(\mathrm{K})$ \\
\hline e & Empirical factor (valued 4.67) & $t_{d u r}$ & Total fire duration (s) \\
\hline$C_{p}$ & Specific heat capacity $(\mathrm{J} / \mathrm{kg} \cdot \mathrm{K})$ & $U$ & External wind speed $(\mathrm{m} / \mathrm{s})$ \\
\hline$d_{e q}$ & $\begin{array}{l}\text { Characteristic length scale of an } \\
\text { external structural element (m) }\end{array}$ & $w_{f}$ & EVF width (m) \\
\hline & Gravitational acceleration $\left(9.81 \mathrm{~m} / \mathrm{s}^{2}\right)$ & $W_{v}$ & Opening width (m) \\
\hline$H_{v}$ & Opening height $(\mathrm{m})$ & $z$ & Height from the opening lintel (m) \\
\hline$y$ & Extinction coefficient $\left(\mathrm{m}^{-1}\right)$ & $Z_{n}$ & Height of neutral plane (m) \\
\hline$l_{x}$ & $\begin{array}{l}\text { Length along the EVF centerline, } \\
\text { originating at the opening }(\mathrm{m})\end{array}$ & Greek & \\
\hline$n_{f}$ & Fuel mass $(\mathrm{kg})$ & $\alpha_{c}$ & Convective heat transfer coefficient $\left(\mathrm{W} / \mathrm{m}^{2} \mathrm{~K}\right)$ \\
\hline$\dot{Q}$ & Heat Release Rate (MW) & $\lambda$ & Flame thickness (m) \\
\hline$q^{\prime \prime}$ & Heat flux to the façade $\left(\mathrm{kW} / \mathrm{m}^{2}\right)$ & $\varepsilon_{z}$ & Local emissivity of the flame (-) \\
\hline$Q_{f}$ & Fire load density $\left(\mathrm{MJ} / \mathrm{m}^{2}\right)$ & $\rho_{a m b}$ & Air density at ambient conditions $\left(\mathrm{kg} / \mathrm{m}^{3}\right)$ \\
\hline$R H$ & Relative humidity (\%) & $\rho_{500 o C}$ & Air density at $500^{\circ} \mathrm{C}\left(\mathrm{kg} / \mathrm{m}^{3}\right)$ \\
\hline$T_{a m b}$ & Ambient temperature $(\mathrm{K})$ & $\sigma$ & $\begin{array}{l}\text { Stefan Boltzmann constant }\left(5.67 \times 10^{-8}\right. \\
\left.\mathrm{W} / \mathrm{m}^{2} \mathrm{~K}^{4}\right)\end{array}$ \\
\hline$T_{f}$ & Temperature of the flame $(\mathrm{K})$ & $\varphi_{z}$ & Configuration factor (radiation from EVF) \\
\hline$T$ & $\begin{array}{l}\text { Temperature at the centre of the } \\
\text { opening }(\mathrm{K})\end{array}$ & $\varphi_{f}$ & $\begin{array}{l}\text { Configuration factor (radiation from fire } \\
\text { through windows) }\end{array}$ \\
\hline
\end{tabular}




\section{INTRODUCTION}

When a building fire is fully developed, flames may spill out of external openings, forming Externally Venting Flames (EVF), also known as façade fires. It is well established that EVF may significantly increase the risk of fire spreading to higher floors or adjacent buildings [1]. EVF may occur under both over-ventilated (OV) and under-ventilated (UV) fire conditions. During the initial stages of a compartment fire (pre-flashover stage), combustion is constrained at the interior of the compartment. When the fire is further evolved, flames in the ceiling jet may become long enough to eject from the compartment openings; in this case, EVF can be observed when the fire is still fuel-controlled. If the fire becomes ventilationcontrolled (post-flashover stage), unburnt volatiles may eject from the opening; they are then mixed with ambient air and ignite, forming EVF.

In the case a fire erupts at the interior space of a building, it is possible for glass panes in windows to fail, thus forming compartment openings which increase the risk of EVF occurrence. Hazards associated with EVF are even greater in high-rise buildings. It is widely recognized that the fire behaviour of high-rise buildings is rather challenging in terms of fire safety as they involve some additional features compared to "conventional" low-rise building [1]. For example, combustible façade systems may pose an increased fire hazard during installation and construction prior to complete finishing and protection of such systems (e.g. Beijing Television Cultural Centre fire in 2009 and the Residential Building fire in 2010). Evacuation strategies in high-rise buildings are also a major safety issue. In addition, in high-rise buildings, as a part of energy efficient building techniques, there is an extensive use of external façade insulation wall systems such as Structural Insulation Panel Systems (SIPS), External Thermal Insulating Composite Systems (ETICS), Aluminium Composite Panels (ACP) and Metal Composite Material (MCM) claddings. Even though these systems may show superior energy-saving performance, in case they ignite it is possible to promote flame spread very fast and produce large amounts of gaseous toxic products. Table 1 reports a number of indicative recent high-rise building fires around the world, involving external fire spread via the building façade; this has also been the case in numerous other high rise building fires, highlighting the importance of understanding the mechanisms of fire spread due to EVF. In fire events where EVF are observed, external wall claddings are usually ignited, thus increasing the complexity of the observed fire spread mechanisms. For instance, in the CCTV building fire in 2009 [2] and the Marina Torch Tower fire in 2015 [3], the fire, counter-intuitively, was observed to spread downwards along the façade.

Façade fires represent $1.3-3.0 \%$ of the total number of building fires [4]. Building fires involving EVF appear to predominately occur in countries with poor regulatory controls concerning facades. The main fire safety aspects of such fire events concern façade heat flux and EVF plume characteristics [5], fire resistance of the façade assembly for load and non-load bearing structures and fire spread on the external surface or at the interior of a façade assembly [4]. Under-ventilated fire events generate the larger hazard in a structure regarding the heat flux impact and EVF development. The structural fire resistance of a façade assembly or a façade-floor junction can be assessed by performing standard fire resistance tests in conjunction with structural analysis depending on the properties of each façade component. In cases that the façade assembly contains combustible components, the additional heat due to fire spreading at the exterior surface of the façade should also be taken into account. However, the majority of current fire safety protection codes worldwide are lacking specific methodologies to evaluate the risks associated with EVF. For instance, the Eurocode design guidelines used across the European Union region, do not specifically address EVF-related risks. In order to implement specific actions towards EVF prevention, the following objectives should be met: protection against fire spread along the façade, maintaining the function of the fire compartmentation, projection against falling objects, reaction to fire requirements for components in the external wall and protection against fire spread between windows.

The key aspects of most fire safety regulations in relation to the fire performance of façades are mainly focused on the reaction to fire requirements for exterior wall assemblies and materials, fire stopping/barrier requirements for interior and exterior walls, separation distances of buildings and openings between stories, minimum separation distances of unprotected openings from a relevant boundary and requirements for sprinkler protection [4]. Nevertheless, aiming to develop a solid base for evaluation, testing and fire mitigation strategies for exterior façade systems potentially exposed to EVF, it is essential to fully comprehend the main phenomena characterising EVF. 
In this context, the main aim of this work is to investigate the fundamental thermal phenomena governing EVF development and their impact on façade systems. Motivated by an increasing number of recent reports $[4,5,6]$ suggesting that existing engineering design methodologies cannot describe with sufficient accuracy the thermal characteristics of EVF, this work emphasizes on the assessment of empirical correlations and design methodologies used to describe EVF and their impact on façade systems. Focusing on the thermal characteristics of EVF that affect the fire safety of a façade system, namely the EVF centreline temperature $\left(T_{z}\right)$ and the EVF-induced heat flux to the façade $(q$ "), the predictive accuracy of various design correlations is evaluated by means of comparison with medium- and large-scale fire tests conducted by the authors and found in literature.

Table 1. Indicative cases of recent high-rise façade fires.

\begin{tabular}{|c|c|c|c|c|}
\hline Building & Location & Year & $\begin{array}{c}\text { Type of façade } \\
\text { system } \\
\end{array}$ & Details \\
\hline $\begin{array}{l}\text { Ajman One } \\
\text { residential } \\
\text { cluster }\end{array}$ & $\begin{array}{l}\text { Ajman, United } \\
\text { Arab Emirates } \\
\quad(\mathrm{UAE})\end{array}$ & 2016 & $\begin{array}{l}\text { Highly combustible } \\
\text { plastic filled ACP }\end{array}$ & $\begin{array}{l}\text { The fire erupted at a building in the } \\
\text { Ajman One residential cluster of } 12 \\
\text { towers and spread to at least one other } \\
\text { tower, } 1 \text { injury, external fire spread [7] }\end{array}$ \\
\hline $\begin{array}{l}\text { Address } \\
\text { Hotel }\end{array}$ & Dubai, UAE & 2016 & $\begin{array}{l}\text { Highly combustible } \\
\text { plastic filled ACP }\end{array}$ & $\begin{array}{c}\text { Fire started on the } 20^{\text {th }} \text { floor of the } \\
\text { building and only affected the exterior of } \\
\text { the structure, } 16 \text { injuries, external fire } \\
\text { spread [8] }\end{array}$ \\
\hline $\begin{array}{l}\text { Docklands } \\
\text { Apartment } \\
\text { Tower }\end{array}$ & $\begin{array}{l}\text { Melbourne, } \\
\text { Australia }\end{array}$ & 2015 & $\mathrm{ACP}$ & $\begin{array}{l}\text { Fire started from an unextinguished } \\
\text { cigarette on the sixth-floor balcony, no } \\
\text { deaths or injuries, external fire spread [9] }\end{array}$ \\
\hline $\begin{array}{l}\text { Marina } \\
\text { Torch } \\
\text { Tower }\end{array}$ & Dubai, UAE & 2015 & $\begin{array}{l}\text { Highly combustible } \\
\text { plastic filled ACP }\end{array}$ & $\begin{array}{l}\text { Fire started in the middle of the tower } \\
\text { before spreading downwards, no deaths or } \\
\text { injuries, external fire spread [3] }\end{array}$ \\
\hline $\begin{array}{l}\text { Residential } \\
\text { Building }\end{array}$ & Grosny, Russia & 2013 & Ventilated façade & $\begin{array}{l}\text { Fire started from a short circuit in an air- } \\
\text { condition, no deaths or injuries, external } \\
\text { fire spread [10] }\end{array}$ \\
\hline $\begin{array}{l}\text { Polat } \\
\text { Tower }\end{array}$ & $\begin{array}{l}\text { Istanbul, } \\
\text { Turkey }\end{array}$ & 2012 & Ventilated façade & $\begin{array}{c}\text { Fire burned through the building's } \\
\text { external insulation, no deaths or injuries, } \\
\text { external fire spread [10] }\end{array}$ \\
\hline $\begin{array}{l}\text { Al Baker } \\
\text { Tower } 4\end{array}$ & Sharjah, UAE & 2012 & $\begin{array}{l}\text { Highly combustible } \\
\text { plastic filled ACP }\end{array}$ & $\begin{array}{l}\text { Fire started at by a lit cigarette thrown on } \\
\text { a balcony, no deaths or injuries, external } \\
\text { fire spread [11] }\end{array}$ \\
\hline $\begin{array}{l}\text { Mermoz } \\
\text { Tower }\end{array}$ & $\begin{array}{l}\text { Roubaix, } \\
\text { France }\end{array}$ & 2012 & Ventilated façade & $\begin{array}{l}\text { Fire initiated at the second floor and } \\
\text { spread rapidly upwards, } 1 \text { fatality, } 10 \\
\text { injuries, external fire spread [10] }\end{array}$ \\
\hline $\begin{array}{l}\text { Wanxin } \\
\text { Complex } \\
\text { Fire }\end{array}$ & $\begin{array}{l}\text { Shenyang, } \\
\text { China }\end{array}$ & 2011 & $\mathrm{ACP}$ & $\begin{array}{c}\text { Fire caused from explosive fireworks, } \\
\text { external fire spread [12] }\end{array}$ \\
\hline $\begin{array}{l}\text { Residential } \\
\text { Building }\end{array}$ & Dijon, France & 2010 & $\begin{array}{c}\text { ETICS (EPS } \\
\text { insulation, mineral } \\
\text { wool fire barriers) }\end{array}$ & $\begin{array}{c}\text { Arson fire started at the basis of the } \\
\text { building from waste containers, } 7 \\
\text { fatalities [10] }\end{array}$ \\
\hline $\begin{array}{l}\text { Residential } \\
\text { Building }\end{array}$ & $\begin{array}{l}\text { Shanghai, } \\
\text { China }\end{array}$ & 2010 & $\begin{array}{l}\text { ETICS (under } \\
\text { construction) }\end{array}$ & $\begin{array}{l}\text { Fire during renovation for installing } \\
\text { exterior wall insulations, } 58 \text { fatalities, } 71 \\
\text { injuries, external fire spread [12] }\end{array}$ \\
\hline $\begin{array}{l}\text { Television } \\
\text { Cultural } \\
\text { Centre } \\
\text { (CCTV) }\end{array}$ & Beijing, China & 2009 & $\begin{array}{l}\text { Ventilated façade } \\
\text { (polystyrene } \\
\text { insulation) }\end{array}$ & $\begin{array}{c}\text { Fire caused from highly explosive } \\
\text { fireworks at construction site on the roof } \\
\text { fire spread, } 1 \text { fatality, } 7 \text { injuries, external } \\
\text { fire spread [2] }\end{array}$ \\
\hline
\end{tabular}




\section{FIRE ENGINEERING DESIGN CORRELATIONS RELATED TO EVF}

A detailed review and comparative assessment of the most widely used fire engineering design correlations, capable of describing the main characteristics of EVF that affect the fire safety of a building, has been performed previously by the authors [5]. These correlations can be used to estimate the geometrical and thermal characteristics of EVF, such as height, projection, width and centreline temperature, as well as EVF-induced heat flux on the façade. The semi-empirical correlations are commonly derived using simplified theoretical analyses in conjunction with experimental data [13, 14]. The correlations investigated in this work correspond to the state-of-the-art correlations currently available in the open literature. They are organised in two main categories, for the estimation of (a) EVF centreline temperature and (b) EVFinduced heat flux to the façade; their main characteristics, are briefly presented in the following sections.

\subsection{EVF Centreline Temperature}

A range of semi-empirical correlations to estimate the EVF centreline temperature rise above the ambient temperature as a function of height is shown in Table 2. In the majority of the investigated correlations, there is a strong dependence of the centreline temperature to the heat release rate. The height $(z)$ used in the presented correlations corresponds either to the height above the opening spandrel (T1, T3 and T4) or the height above the virtual source (T2), estimated according to the methodology proposed by Yokoi [14]. In EN 1991-1-2 [15], different correlations are proposed when either No Forced Draught (NoFD) or Force Draught (FD) ventilation conditions are established; in the former case, openings are present only on one side of the fire compartment, whereas in the latter case, there are openings on opposite sides of the fire compartment or additional air is being fed to the fire from another source (e.g. mechanical ventilation). In Figure 1, the most important parameters used in the correlations, as well as the EVF shape assumed for NoFD and FD ventilation conditions, are depicted.

Table 2. Semi-empirical correlations for the estimation of the EVF centerline temperature.

\begin{tabular}{|c|c|c|c|c|}
\hline Abbr. & Ref. & & NoFD & FD \\
\hline $\mathrm{T} 1$ & [15] & $T_{z}=$ & $\left(1.0-0.4725 \frac{l_{x} W_{v}}{\dot{Q}}\right)\left(T_{o}-T_{a m b}\right)$ & $T_{z}=\left(1.0-0.3325 \frac{l_{x} A_{0}^{1 / 2}}{\dot{Q}}\right)\left(T_{o}-T_{a m b}\right)$ \\
\hline $\mathrm{T} 2$ & [16] & \multicolumn{3}{|c|}{$\left(T_{z}+273.15\right)=24.6(\dot{Q} / 1000)^{2 / 3} z^{-5 / 3}$} \\
\hline T3 & [14] & \multicolumn{3}{|c|}{$=\left\{\begin{array}{l}2.0 \frac{\dot{Q}^{2 / 3}}{C_{p}^{2 / 3} \rho_{500^{\circ} C}^{2 / 3} g^{1 / 3} T_{a m b}^{-1 / 3}\left(H_{v}-Z_{n}\right)}, \text { when } \frac{z}{Z_{n}} \leq 0.3 \\
2.0 \frac{\dot{Q}^{2 / 3}}{C_{p}^{2 / 3} \rho_{500^{\circ} C}^{2 / 3} g^{1 / 3} T_{a m b}^{-1 / 3}\left(H_{v}-Z_{n}\right)}, \text { when } \frac{z}{Z_{n}}>0.3\end{array}\right.$} \\
\hline $\mathrm{T} 4$ & [17] & \multicolumn{3}{|c|}{$\begin{array}{c}2.0 \frac{(\dot{Q} / 1000)^{2 / 3}}{C_{p}^{2 / 3} \rho_{a m b}^{2 / 3} g^{1 / 3} T_{a m b}^{-1 / 3}\left(H_{v}-Z_{n}\right)} \text {, when } \frac{z}{H_{v}-Z_{n}}<0.64 \\
1.6 \frac{(\dot{Q} / 1000)^{2 / 3} z^{-1 / 2}}{C_{p}^{2 / 3} \rho_{a m b}{ }^{2 / 3} g^{1 / 3} T_{a m b}^{-1 / 3}\left(H_{v}-Z_{n}\right)} \text {, when } 0.64 \leq \frac{z}{H_{v}-Z_{n}} \leq 2.44 \\
2.5 \frac{(\dot{Q} / 1000)^{2 / 3} z^{-1}}{C_{p}^{2 / 3} \rho_{a m b}{ }^{2 / 3} g^{1 / 3} T_{a m b}^{-1 / 3}}, \text { when } \frac{z}{H_{v}-Z_{n}}>2.44\end{array}$} \\
\hline
\end{tabular}

Fig. 1. Schematic of important parameters and assumed EVF shape, for NoFD (left) and FD (middle) conditions; front view of the compartment-facade configuration (right).

\subsection{EVF-Induced Heat Flux Estimation}

Aiming to estimate the EVF-induced heat flux on the façade, EVF are commonly modelled as a vertical plane adjacent to the façade; their heat flux levels are mainly influenced by the fire compartment geometry, heat release rate, ambient conditions (e.g. temperature, wind speed) and compartment temperature [18-21]. Generally, the heat balance for each point of a façade exposed to EVF can be expressed using Eq. (1). 
$\dot{q}^{\prime \prime}=\dot{q}_{\text {conv }}^{\prime \prime}+\dot{q}_{\text {rad }}^{\prime \prime}=a_{c}\left(T_{z}-T_{\text {wall }}\right)+\varepsilon_{z} \varphi_{z} \sigma T_{z}^{4}+\varphi_{f} \sigma T_{f}^{4}-\sigma T_{\text {wall }}^{4}$

The local emissivity of the flame $\left(\varepsilon_{z}\right)$ and the convective heat transfer coefficient $\left(\alpha_{c}\right)$ are commonly estimated using Eq. (2) and Eq. (3) or (4), respectively.

$\varepsilon_{z}=1-\exp (-k \lambda)$

$\alpha_{c}=c\left(\frac{\dot{Q}}{A_{v}}\right)^{0.6}\left(\frac{1}{d_{e q}}\right)^{0.4}$

$\alpha_{c}=9.8\left(\frac{\dot{Q}}{17.85 A_{v}}+\frac{U}{1.6}\right)^{0.6}\left(\frac{1}{d_{e q}}\right)^{0.4}$

In various heat flux calculation methodologies, including EN1991-1-2 [15], it is suggested to use predefined values for the extinction $(k)$ and the convection heat transfer $\left(\alpha_{c}\right)$ coefficients for exposed and unexposed members, regardless of the type of the fuel, its burning rate and the EVF geometric characteristics. In the current work, the impact of various physical parameters that may actually influence the EVF's thermal impact to the façade, is investigated by means of comparison with available experimental data. Two main parameters are investigated, namely the effect of the fuel type on the extinction coefficient $(k)$ and the the convective heat transfer coefficient $\left(\alpha_{c}\right)$. A key parameter analysis, presented in a previous work [5], revealed that the EVF shape does not significantly influence the estimated heat flux levels.

Four different models, namely HF1-HF4, presented in Table 3, are used for the estimation of the radiative and convective heat transfer components of the EVF-induced heat flux. In all the examined models, the total heat flux is estimated using Eq. (1), by assuming $\varphi_{z}=1$ and neglecting the last two terms on the right hand side [5]; when relevant measurements were not available, the required EVF centreline temperature $\left(T_{z}\right)$ was estimated using correlation $\mathrm{T} 1$.

Table 3. Investigated methodologies for the estimation of EVF-induced heat flux to the façade.

\begin{tabular}{|c|c|c|}
\hline \multirow{2}{*}{ Abbr. } & Radiative Heat Transfer & Convective Heat Transfer \\
\cline { 2 - 3 } & $k\left(\mathrm{~m}^{-1}\right)$ & $a_{c}\left(\mathrm{~W} / \mathrm{m}^{2} \mathrm{~K}\right)$ \\
\hline HF1 & 0.3 & Eq. $(3)$ \\
\hline HF2 & $k_{\text {fuel }}($ Table 4$)$ & Eq. $(3)$ \\
\hline HF3 & 0.3 & $25[15]$ \\
\hline HF4 & 0.3 & Eq. $(4), 1 / d_{e q}=1.0$ \\
\hline
\end{tabular}

Model HF1 serves as a base-case scenario, by assuming a constant $k$ value (0.3) and using Eq. (3) to estimate $a_{c}$. Aiming to improve the accuracy of the EVF-induced heat flux estimations, the effect of using fuel-dependent extinction coefficient values is investigated in model HF2. The $k_{f u e l}$ values used for each test case, based on the actual fuel employed in the respective fire test, are given in Table 4. The presented bibliographic values are indicative and may provide practical engineering estimates. If more accurate estimations are required, a thorough numerical simulation analysis should be performed, by employing a more rigorous heat transfer methodology. Model HF3 investigates the $25 \mathrm{~W} / \mathrm{m}^{2} \mathrm{~K}$ value proposed in EN1991-1-2 for $a_{c}$, whereas in model HF4, a different correlation, Eq. (4), is used for the estimation of $a_{c}$.

Table 4. Extinction coefficient or monochromatic absorption coefficient for various fuels.

\begin{tabular}{l|l|l} 
Fuel & $k_{\text {fuel }}\left(\mathrm{m}^{-1}\right)$ & Ref.
\end{tabular}




\begin{tabular}{|c|c|c|}
\hline Propane & 13.32 & {$[22]$} \\
\hline City gas/Methane & 6.45 & {$[22]$} \\
\hline Wood cribs & 0.80 & {$[22,23]$} \\
\hline Assorted furniture & 1.13 & {$[22]$} \\
\hline
\end{tabular}

\section{FUNDAMENTAL PHENOMENA AFFECTING EVF}

It is well established that during a fire event, one of the weakest links in a building is its window glass. Due to the thermal stresses, normal glass may crack and fall out when exposed to relatively low temperatures and radiant heat fluxes [24]. In a fully developed fire, flames may spill out of external openings (e.g. windows) in case the glazing fails. Fire compartment and opening geometry and the prevailing ventilation conditions are the most significant parameters influencing the EVF geometric and thermal characteristics $[5,6,13,15,18,19,25]$. During the initial stages of the fire, compartment geometry is important since enclosure dimensions are decisive on how close the initial fire is located in relation to other combustible materials, ventilation openings and compartment boundaries. Openings severely impact the fire behaviour because as soon as flaming combustion occurs the fire becomes dependent on oxygen availability in order to maintain itself; they also control fire growth rate and compartment temperature. If a wall exists above the opening through which the EVF emerges, the temperature difference between the fire plume and ambient air creates a strong buoyant current that causes EVF to move upwards. Horizontal projections and spandrels have also been found to greatly influence the EVF characteristics [20]. Recently, the effect of balconies on the fire spread via external windows into upper floors was experimentally and numerically investigated [26]. The absence of a balcony between windows of successive floors allows EVF to move along the façade; in case there is a balcony, the risk of fire spread into the upper floors is reduced. However if the balcony is of the same width as the opening, there is a high lateral EVF spread and as a result the limiting of the EVF spread is not as effective. Additionally, ventilation conditions, such as Forced Draught (FD) and No Forced Draught (NoFD) modes play an important role in EVF development $[5,18,19]$. When external wind is blowing parallel to the building façade, EVF will eventually deflect horizontally to the side of the opening. This may affect openings on the adjacent compartments or even compartments located in higher levels.

Table 5. Review on fundamental experimental (Exp.), numerical (Num.) and theoretical (Th.) studies on EVF and their effects on the façade.

\begin{tabular}{|c|c|c|c|c|c|c|c|}
\hline No. & Ref. & Exp. & Num. & Th. & \multicolumn{2}{|c|}{ Scale } & \multirow{2}{*}{ Short description } \\
\hline 1 & {$[21]$} & $\times$ & $\times$ & $\checkmark$ & $\checkmark$ & $\times$ & $\begin{array}{c}\text { Revisiting EVF physics and suggesting two } \\
\text { new length scales for over- and under- } \\
\text { ventilated fires }\end{array}$ \\
\hline 2 & {$[27]$} & $\checkmark$ & $\checkmark$ & $\times$ & $\times$ & $\checkmark$ & $\begin{array}{c}\text { Formation and validation of a simplified } \\
\text { model for heat flux estimation due to EVF }\end{array}$ \\
\hline 3 & {$[17]$} & $\checkmark$ & $\times$ & $\times$ & $\checkmark$ & $\times$ & $\begin{array}{c}\text { Formation and validation of a model for } \\
\text { EVF prediction with emphasis on wall } \\
\text { attachment }\end{array}$ \\
\hline 4 & {$[29]$} & $\checkmark$ & $\times$ & $\times$ & $\checkmark$ & $\times$ & $\begin{array}{c}\text { Investigation of ventilation conditions effect } \\
\text { on EVF and heat fluxes at the facade }\end{array}$ \\
\hline 5 & {$[18]$} & $\checkmark$ & $\checkmark$ & $\times$ & $\checkmark$ & $\times$ & $\begin{array}{c}\text { Full scale study of the EVF associated } \\
\text { phenomena under realistic fuel loads }\end{array}$ \\
\hline 6 & {$[30]$} & $\checkmark$ & $\times$ & $\times$ & $\times$ & $\checkmark$ & $\begin{array}{c}\text { Formation of a model for estimation of heat } \\
\text { release due to combustion of excess fuel in } \\
\text { EVF }\end{array}$ \\
\hline 7 & {$[20]$} & $\checkmark$ & $\times$ & $\checkmark$ & $\times$ & $\checkmark$ & $\begin{array}{c}\text { Investigation of façade exposure due to EVF. } \\
\text { Identification of parameters influencing } \\
\text { thermal exposure }\end{array}$ \\
\hline 8 & {$[13]$} & $\checkmark$ & $\times$ & $\checkmark$ & $\times$ & $\checkmark$ & Formation and validation of a set of \\
\hline
\end{tabular}




\begin{tabular}{|c|c|c|c|c|c|c|c|}
\hline & & & & & & & $\begin{array}{c}\text { correlations to predict the effects of EVF on } \\
\text { the heating of external structural elements }\end{array}$ \\
\hline 9 & {$[30]$} & $\checkmark$ & $\times$ & $\times$ & $\times$ & $\checkmark$ & $\begin{array}{c}\text { Investigation of EVF projection and } \\
\text { correlation with fuel load }\end{array}$ \\
\hline 10 & {$[31]$} & $\checkmark$ & $\times$ & $\times$ & $\times$ & $\checkmark$ & Investigation of EVF physical characteristics \\
\hline 11 & {$[14]$} & $\checkmark$ & $\times$ & $\checkmark$ & $\checkmark$ & $\checkmark$ & Investigation of EVF physical characteristics \\
\hline
\end{tabular}

Research on EVF has been carried out since the 1960s as illustrated in Table 5. A number of medium- and large-scale fire tests combined with numerical simulations have proven useful in the identification of the physicals aspects of EVF and of the parameters affecting their development. Initial research efforts focused on the identification and characterization of the main EVF physical characteristics and their dependency on fuel load and the geometrical characteristics of the compartment [14, 30, 31]. The first correlations used to describe the EVF physical characteristics were developed in the 1960s by Yokoi [14] and further evaluated and improved in the 1980s by Law [13]. At a later stage, Oleszkiewicz [26] pointed his research towards EVF exposure of facades, by identifying the main parameters influencing the induced thermal exposure. The first thorough study on the effects of ventilation conditions, except of the initial work of Law [13], was conducted by Klopovic [18, 19] and Huang [28]. The Law model was revisited by Empis in her wellgrounded work on the parameters influencing the heat flux incident on facades [27]. Later on, a number of models for predicting EVF characteristics and their impact on facades have been developed by other researchers [17, 29]. More recently, Lee and co-workers [21] revisited the EVF physics by introducing two new length scales to describe EVF evolution in over-ventilated (OV) and under-ventilated (UV) conditions.

\section{EXPERIMENTAL INVESTIGATION OF EVF}

\subsection{Medium-scale façade fire test}

In the frame of the current study, a series of fire tests was conducted in a medium-scale compartmentfaçade fire facility. The compartment was a $1 / 4$ scale model of an ISO 9705 room [32]. The internal compartment dimensions were $0.60 \mathrm{~m} \times 0.90 \mathrm{~m} \times 0.60 \mathrm{~m}$; the external facade wall measured $0.658 \mathrm{~m} \times 1.8$ $\mathrm{m}$. A double layer of $0.0125 \mathrm{~m}$ thick fire-resistant gypsum plasterboards was used as the internal (compartment) and external (façade) lining material. The fire compartment opening, corresponding to an open door, located at the middle of the northern wall, measured $0.20 \mathrm{~m} \times 0.50 \mathrm{~m}$. A range of realistic fire scenarios, relevant to building fires, was developed for the EFV measurement campaign. The majority of the actual furniture found in contemporary residential environments consists of hydrocarbon-based thermoplastic materials, including plastics and foams that, when ignited, melt and burn similar to liquidfuel pool fires. In this context, aiming to simulate realistic building fire conditions, an "expendable" liquid fuel (n-hexane) pool fire source was employed. Recording of the dynamic behaviour of the EVF was carried out using a selectively distributed network of sensors that allowed monitoring of important physical parameters, such as flame envelope geometry, gas and wall surface temperatures, façade heat flux, fuel mass loss and gas species concentrations. A total of 102 thermocouples (1.5 mm K-type) has been employed to record the temporal evolution of gas and solid surface temperatures; the EVF shape was estimated using an in-house developed image processing tool [6]. A schematic of the experimental facility, illustrating the locations of the employed measuring devices, is given in Fig. 2 [33].

A thorough repeatability analysis has been presented in a previous work [33], by performing three identical tests in the same medium-scale façade fire test facility; it has been demonstrated that good levels of experimental repeatability are achieved. A parametric study was performed, by varying the total fuel load (test cases 1,2 and 3) and the opening dimensions (test case 4). The fire load used in test cases 2 and 4 was identical; the former case corresponds to a "door" opening, whereas the latter case refers to a "window" opening. A summary of the main operational parameters, i.e. initial fuel mass $\left(m_{f}\right)$, fire load density $\left(Q_{f}\right)$, opening height $\left(H_{v}\right)$ and width $\left(W_{v}\right)$ and average total heat release rate $(\dot{Q})$ for all the examined test cases is given in Table 6. 
Fig. 2. General layout (left) and characteristic image (right) of a medium-scale façade fire test.

The average heat release rate $(\dot{Q})$ has been calculated by means of the experimental fuel consumption rate and the lower heating value of $n$-hexane $(43521 \mathrm{~kJ} / \mathrm{kg})$, estimated using an isoperibolic bomb calorimeter. Test cases 2, 3 and 4 corresponded to under-ventilated fire conditions [6]. Experimental results suggest the existence of three characteristic EVF phases, namely "Internal Flaming" (IF) corresponding to the initial period when combustion is limited at the interior of the fire compartment, "Intermittent Flame Ejection" (IFE), when flame jets appear intermittently outside the compartment and the "Continuous External Flame" (CEF) period that essentially spans the time period when EVF are consistently ejecting through the opening [33].

Table 6. Summary of main operational parameters for the examined test cases.

\begin{tabular}{|c|c|c|c|c|c|}
\hline \multicolumn{2}{|c|}{ Test Case } & $\mathbf{1}$ & $\mathbf{2}$ & $\mathbf{3}$ & $\mathbf{4}$ \\
\hline$m_{f}$ & $(\mathrm{~kg})$ & 0.655 & 1.539 & 3.078 & 1.539 \\
\hline$Q_{f}$ & $\left(\mathrm{MJ} / \mathrm{m}^{2}\right)$ & 53.18 & 125.0 & 250.0 & 125.0 \\
\hline$H_{v}$ & $(\mathrm{~m})$ & 0.5 & 0.5 & 0.5 & 0.3 \\
\hline$W_{v}$ & $(\mathrm{~m})$ & 0.2 & 0.2 & 0.2 & 0.2 \\
\hline$\dot{Q}$ & $(\mathrm{~kW})$ & 79.0 & 207.0 & 233.0 & 105.0 \\
\hline
\end{tabular}

\subsection{Large-scale façade fire test}

Aiming to further investigate the fundamental characteristics of EVF, a large-scale fire test was performed at the premises of the Greek Fire Academy [34]. A timber frame compartment was lined with two layers of $0.0125 \mathrm{~m}$ fire resistant gypsum plasterboards. The internal dimensions of the test compartment measured $1.760 \mathrm{~m} \times 0.800 \mathrm{~m} \times 2.100 \mathrm{~m}$ (Fig. 3). The compartment exhibits a single opening (window), measuring $0.765 \mathrm{~m} \times 1.100 \mathrm{~m}$. The external façade wall measured $2.614 \mathrm{~m} \times 5.230 \mathrm{~m}$. The window is located on the south side; the distance of the window sill from the compartment's floor is $0.940 \mathrm{~m}$. A ventilated façade system was installed on the south side of the compartment. The internal façade surface was formed using commercial $0.015 \mathrm{~m}$ thick gypsum plasterboard; timber studs and battens were used to support the façade on top of the compartment. The external cladding panels, comprising $0.0125 \mathrm{~m}$ thick cement boards covered by a $0.005 \mathrm{~m}$ thick layer of plaster coating, were supported using perforated steel studs the width of the air cavity formed between the two layers is $0.025 \mathrm{~m}$. An extensive set of sensors was installed both inside and outside the test compartment, aiming to record the temporal variation of several important physical parameters, such as gas and wall surface temperatures, gas velocities and mass loss rate. Emphasis was given to the characterization of the temperature environment adjacent to the façade wall along the height of the EVF plume.

A stainless steel rectangular pan, measuring $0.700 \mathrm{~m} \times 0.700 \mathrm{~m} \times 0.250 \mathrm{~m}$, was installed at the geometrical centre of the room, $0.1 \mathrm{~m}$ above the compartment floor, holding the $56.7 \mathrm{~kg}$ of liquid $\mathrm{n}$-hexane used as fire load. The lower heating value of the n-hexane used in the tests was estimated, using an isoperibolic oxygen bomb calorimeter, to be $43521 \mathrm{~kJ} / \mathrm{kg}$. The fuel mass was continuously monitored using a load cell, installed under the pan. This "expendable" fuel source was employed to better simulate realistic building fire conditions. The fire load and opening dimensions were selected in order to establish strongly underventilated fire conditions, thus ensuring the development of an EVF. The peak fire power achieved, estimated using the instantaneous fuel mass loss rate, was $2.76 \mathrm{MW}$.

Fig. 3. General layout (left) and characteristic image (right) of the large-scale compartment-façade fire test.

\subsection{Additional medium- and large-scale façade fire tests}

Aiming to validate and comparatively assess the fire engineering design correlations and methodologies presented in Section 3, predictions are compared to EVF centreline temperatures measurements obtained in the aforementioned medium-scale (Section 4.1) and large-scale (Section 4.2) façade fire tests. In order to 
further broaden the scope of the validation study for the investigated empirical correlations and models, an additional large set of measurements, obtained in various large-scale fire tests found in the literature, was also used. The main characteristics of each fire test, such as compartment geometry, ventilation characteristics and fire power, are presented in detail in Table 7. The ventilation regimes for each test case are also tabulated; the majority of the cases correspond to ventilation-controlled fires (UV).

Table 7. Main characteristics of the medium- and large-scale fire tests used in the validation study.

\begin{tabular}{|c|c|c|c|c|c|c|c|c|c|}
\hline $\begin{array}{c}\text { Test } \\
\text { Case }\end{array}$ & Ref. & Scale & $\begin{array}{c}W \times D \times H \\
\left(\mathrm{~m}^{3}\right)\end{array}$ & $\begin{array}{c}A_{o} \\
\left(\mathrm{~m}^{2}\right)\end{array}$ & $\begin{array}{c}A_{o, F D} \\
\left(\mathrm{~m}^{2}\right)\end{array}$ & $\begin{array}{c}\text { Vent. } \\
\text { Cond. }\end{array}$ & $\begin{array}{c}\dot{Q} \\
(\mathrm{MW})\end{array}$ & $\begin{array}{c}t_{\text {dur }} \\
(\mathrm{min})\end{array}$ & $\begin{array}{c}\text { Vent. } \\
\text { Regime }\end{array}$ \\
\hline 1 & {$[33]$} & Medium & $0.6 \times 0.9 \times 0.6$ & $0.2 \times 0.5$ & - & NoFD & 0.079 & 6.2 & OV \\
\hline 2 & {$[33]$} & Medium & $0.6 \times 0.9 \times 0.6$ & $0.2 \times 0.5$ & - & NoFD & 0.207 & 3.9 & UV \\
\hline 3 & {$[33]$} & Medium & $0.6 \times 0.9 \times 0.6$ & $0.2 \times 0.5$ & - & NoFD & 0.233 & 9.9 & UV \\
\hline 4 & {$[33]$} & Medium & $0.6 \times 0.9 \times 0.6$ & $0.2 \times 0.3$ & - & NoFD & 0.105 & 10.9 & UV \\
\hline 5 & {$[34]$} & Large & $1.7 \times 0.8 \times 2.1$ & $0.8 \times 1.1$ & - & NoFD & 2.76 & 16.0 & UV \\
\hline 6 & {$[18,19]$} & Large & $5.3 \times 3.6 \times 2.4$ & $2.4 \times 1.5$ & - & NoFD & 6.34 & 32.0 & UV \\
\hline 7 & {$[18,19]$} & Large & $5.3 \times 3.6 \times 2.4$ & $2.4 \times 1.5$ & $0.8 \times 2.0$ & FD & 5.03 & 32.0 & UV \\
\hline 8 & {$[20]$} & Large & $5.9 \times 4.4 \times 2.8$ & $2.6 \times 2.7$ & - & NoFD & 10.3 & 30.0 & OV \\
\hline 9 & {$[27]$} & Large & $3.6 \times 4.8 \times 2.5$ & $2.4 \times 1.2$ & $\begin{array}{c}0.9 \times 1.9 \\
0.9 \times 2.0\end{array}$ & FD & 8.8 & 19.0 & UV \\
\hline 10 & {$[35]$} & Large & $3.0 \times 4.3 \times 1.7$ & $2.0 \times 1.00$ & - & NoFD & 2.8 & 5.0 & UV \\
\hline 11 & {$[35]$} & Large & $3.0 \times 4.3 \times 1.7$ & $2.0 \times 1.2$ & $\begin{array}{c}0.5 \times 0.6 \\
(\times 4)\end{array}$ & FD & 4.2 & 5.0 & OV \\
\hline
\end{tabular}

\section{RESULTS AND DISCUSSION}

\subsection{EVF Centreline Temperature}

A comparison of EVF centreline temperature measurements to predictions obtained by using correlations T1-T4 are shown in Fig. 4, where the vertical distribution of measured and predicted time-averaged centreline EVF temperatures are depicted. Correlation T1 is applied only in test case 3 , since in the rest of the cases the total fire power was lower than the correlation's range of applicability. Under low fire load conditions (e.g. test case 1) correlations T2 and T3 are found to over-predict experimental data, whereas correlation T4 shows a remarkable agreement with measured values. In cases of increased fire load (e.g. test case 3), correlations $\mathrm{T} 1$ and $\mathrm{T} 4$ considerably under-predict the measured values, whereas correlations $\mathrm{T} 2$ and $\mathrm{T} 3$ over-predict the experimental data. The point heat source assumption employed in correlation T2 results in a good qualitative agreement with the measured centreline temperatures in test cases 1,2 and 4. Nevertheless, predictions of correlation T2, which is based on the experimental investigation of fire plumes (considered as upward hot currents), do not agree quantitatively with the actual EVF centreline temperature profile, especially near the opening. Yokoi's methodology, correlation T3, over-predicts the experimental data in test cases 1,2 and 3, but appears to accurately estimate temperatures near the opening for all test cases. Correlation T4 shows good qualitative and quantitative agreement in test cases 1, 2 and 4 but slightly under-predicts the measured values in test case 3. Generally, the observed discrepancies between experimental data and correlations may be attributed to the fact that the performed experiments resulted in continuous and consistent EVF, whereas literature reports suggest that the majority of correlations originate from temperature measurements in the fire plume region. Overall, the use of T1 correlation is found to under-estimate the experimental values, but no safe conclusion can be derived since it was only applied in one medium-scale test case. The rest of the correlations, namely T2, T3 and T4, may be safely used (conservative predictions), although they exhibit reduced accuracy in positions near the top of the opening.

Fig. 4. Vertical distribution of measured [38] and predicted time-averaged centreline EVF temperatures; effect of fire load (left) and opening factor (right). 
In Fig. 5, predictions of the vertical distribution of EVF centreline temperatures using correlations T1-T4 (Table 3) are compared to experimental data obtained in the large-scale fire test of Klopovic and Turan [18, 19], and a ventilated façade large-scale fire test [34] performed by the authors. Under No Forced Draught (NoFD) conditions (test case 5), correlation T1 is consistently under-predicting the actual centreline temperature, whereas correlations $\mathrm{T} 3$ and $\mathrm{T} 4$ exhibit a more conservative behaviour (over-prediction); correlation T2 demonstrates a rather inconsistent behaviour. On the other hand, when Forced Draught (FD) conditions are established (test case 7), only correlation T1 is capable of consistently over-estimating the centreline temperature. Correlations originating from the experimental investigation of fire plumes or upward moving hot jets, such as T2 and T4, significantly under-predict the EVF centreline temperature near the opening.

Fig. 5. Vertical distribution of measured $[19,20,39]$ and predicted centreline EVF temperatures for test cases 5 (left) and 7 (right).

\subsection{Heat Flux on the Exposed Façade Surface}

The temporal evolution of the measured and estimated heat flux at the exposed façade surface in the medium-scale façade fire tests are illustrated in Fig. 6; the latter values are estimated using the models presented in Table 3. A typical behaviour of an under-ventilated compartment fire can be observed which is characterized by 3 distinct phases that appear in succession [35].

Fig. 6. Vertical distribution of measured and predicted EVF-induced heat flux on the exposed façade surface; effect of fire load (left) and opening factor (right).

Initially, combustion is constrained in the interior of the fire compartment (IF period) and in the vicinity of the fuel pan an advection stream is created. Gradually, the flame front moves away from the fuel pan, expanding radially and horizontally towards the opening. In that phase, external flame jets and quick flashes appear at the exterior of the fire compartment, signifying the beginning of the IFE stage. As time passes, CEF is observed due to the sustained external combustion of unburnt volatiles, during the quasisteady phase of fully developed fire. Throughout the latter phase, EVF consistently covers the region above the opening resulting in higher values of heat flux in the façade surface.

Model HF1 is used as a base case; it is found to under-predict the experimental data. Model HF2, which takes into account the specific fuel properties for the estimation of the extinction coefficient, results in predictions that err on the safe side, with the exception of test case 4 where a slight under-prediction is observed (approximately 10\%). Less conservative estimations are derived when model HF3 is employed, where a constant value of convective coefficient is used, as proposed in EN 1991-1-2 [15]. When a more rigorous methodology is used to estimate the convective coefficient (model HF4), results are not significantly improved. Based on the aforementioned observations, it appears that the most important influencing parameter is the effect of fuel on the extinction coefficient value (model HF2).

Aiming to further investigate the applicability of the examined fire engineering design correlations, predictions are also compared to the EVF-induced heat flux measurements obtained in 6 large-scale compartment-façade fire tests found in the literature [5]. Table 8 presents a summary of the estimated relative errors for all the examined test cases; positive values indicate "over-prediction" (conservative design values), whereas negative values suggest "under-prediction" (non-conservative design values). Predictions of the heat flux to the façade, in both medium- and large-scale configurations, using various methodologies highlighted the importance of the extinction coefficient $\left(k_{f u e l}\right)$. When model HF2 is used, predicted values generally err on the safe side, under both NoFD and FD conditions. In the case of FD conditions, more conservative predictions are obtained using model HF3, where a constant value for the convective heat transfer coefficient is employed. An attempt to use a more rigorous methodology for the calculation of the convective heat transfer coefficient has not been successful, as demonstrated by the large errors obtained when method HF4 is used. Overall, model HF2, where the effect of the fuel type used in 
each fire test is taken into account, has been found to yield the most conservative results compared to all the other models. Therefore, model HF2 is deemed to be safer for fire engineering design purposes.

Table 8. Relative error (\%) of predicted heat fluxes for all test cases.

\begin{tabular}{|c|c|c|c|c|c|c|c|c|c|c|}
\hline \multirow{2}{*}{$\begin{array}{c}\text { Test } \\
\text { Case }\end{array}$} & \multicolumn{4}{|c|}{ Medium-scale fire tests } & \multicolumn{6}{c|}{ Large-scale fire tests } \\
\cline { 2 - 11 } & 1 & 2 & 3 & 4 & 6 & 7 & 8 & 9 & 10 & 11 \\
\hline HF1 & -53.7 & -48.7 & -67.7 & -156.3 & -43.8 & +124.4 & +60.2 & +12.0 & -25.4 & -74.7 \\
\hline HF2 & +25.9 & +40.4 & +39.9 & -10.5 & -45.7 & +129.9 & +110.6 & +137.9 & -16.0 & -4.4 \\
\hline HF3 & +12.6 & -13.8 & -71.8 & -125.1 & -43.8 & +73.3 & +74.5 & +195.3 & -25.4 & -34.5 \\
\hline HF4 & -257.7 & -224.2 & -249.9 & -595.9 & -83.5 & -29.7 & -34.4 & +133.6 & -81.7 & -67.8 \\
\hline
\end{tabular}

\section{CONCLUDING REMARKS}

Estimation methodologies for the evaluation of the EVF thermal characteristics and the EVF-induced heat flux at the façade were evaluated against available experimental data obtained in a wide range of mediumscale and large-scale compartment-façade fire tests. In terms of the EVF centreline temperature estimation, it has been demonstrated that correlations T2, T3 and T4, where the temperature is a function of the $2 / 3$ power of the heat release rate, may be safely used, although their prediction accuracy close to the opening lintel is generally limited. On the other hand, in correlation T1, which is employed in EN1991-1-2, temperature is inversely proportional to the heat release rate; predictions of correlation $\mathrm{T} 1$ were found to under-estimate the experimental values under NoFD conditions, whereas they errs towards conservative estimations under FD conditions. Predictions of the EVF-induced heat flux to the façade under both NoFD and FD ventilation conditions highlighted the importance of incorporating the nature of the fuel type in the heat balance equation, by using an appropriate estimation for the extinction coefficient (and subsequently the local flame emissivity). This effect is taken into account in model HF2, which yielded the most conservative predictions in both medium- and large-scale configurations. An overall qualitative assessment of the correlations and methodologies investigated in this work is presented in Table 9. The reported results are meant to provide a guideline for fire safety engineers, allowing them to select an appropriate model and to estimate potential errors in calculations of EVF thermal characteristics. Acknowledging the importance of providing adequate safety levels for tenants and structures, the reported results focus on identifying which methodologies and correlations over-predict the experimental results and thus can be "safely" used in fire safety design applications.

Table 9. Qualitative assessment of the employed methodologies for the estimation of EVF centreline temperature and EVF-induced heat flux for fire safety design.

\begin{tabular}{|c|c|c|c|c|c|c|c|}
\hline \multirow{3}{*}{$\begin{array}{c}\text { Physical } \\
\text { Parameter }\end{array}$} & \multirow{3}{*}{$\begin{array}{c}\text { Correlation - } \\
\text { Model }\end{array}$} & \multirow{2}{*}{\multicolumn{2}{|c|}{$\begin{array}{c}\text { Medium scale } \\
\text { NoFD }\end{array}$}} & \multicolumn{4}{|c|}{ Large scale } \\
\hline & & & & \multicolumn{2}{|c|}{ NoFD } & \multicolumn{2}{|c|}{ FD } \\
\hline & & OV & UV & OV & $\mathbf{U V}$ & OV & UV \\
\hline \multirow{4}{*}{$\begin{array}{l}\text { EVF centreline } \\
\text { temperature }\end{array}$} & T1 & OoR & $\checkmark$ & N/A & $x$ & N/A & $\checkmark$ \\
\hline & $\mathrm{T} 2$ & $\checkmark$ & $\checkmark$ & N/A & - & N/A & - \\
\hline & T3 & $\checkmark$ & $\checkmark$ & N/A & $\checkmark$ & N/A & OoR \\
\hline & $\mathrm{T} 4$ & $\checkmark$ & - & N/A & $\checkmark$ & N/A & - \\
\hline \multirow{4}{*}{$\begin{array}{l}\text { EVF-induced } \\
\text { heat flux }\end{array}$} & HF1 & $x$ & $x$ & $\checkmark$ & $\checkmark$ & $x$ & $x$ \\
\hline & HF2 & $\checkmark$ & $\checkmark$ & $\checkmark$ & $\checkmark$ & $\checkmark$ & $\checkmark$ \\
\hline & HF3 & $x$ & $x$ & $\checkmark$ & $\checkmark$ & $\checkmark$ & $\checkmark$ \\
\hline & HF4 & $x$ & $x$ & $x$ & $x$ & $x$ & $x$ \\
\hline
\end{tabular}




\section{ACKNOWLEDGMENTS}

This study has been financially supported by the E.C. in the frame of FP7 project, "MeeFS: Multifunctional Energy Efficient Façade System for Building Retrofitting” (Grant No. 285411). The assistance of Dipl. Eng. Konstantinos Chotzoglou in the testing phase of this work is gratefully acknowledged.

\section{REFERENCES}

[1] J. Sun, L. Hu, Y. Zhang, A review on research of fire dynamics in high rise buildings, Theor. Appl. Mech. Lett. 3 (2013) 1-13, http://dx.doi.org/10.1063/2.1304201.

[2] J. Glancey, Beijing's newest skyscraper survives blaze, The Guardian, 〈http://www.theguardian.com/world/2009/feb/11/television-cultural-centre-tower-beijing-fire〉, 2009.

[3] M. Gray, Fire breaks out at luxury Dubai skyscraper, CNN, 〈http://edition.cnn.com/2015/02/20/middleeast/dubai-tower-fire//, 2015.

[4] N. White, M. Delichatsios, Fire Hazards of Exterior Wall Assemblies Containing Combustible Components 1st edition, Springer Briefs in Fire, Springer, 2014.

[5] E.K. Asimakopoulou, D.I. Kolaitis, M.A. Founti, Assessment of fire engineering design correlations used to describe the geometry and thermal characteristics of Externally Venting Flames, Fire Technol. 53 (2017) 709-739, http://dx.doi.org/10.1007/s10694-016-0594-2.

[6] E.K. Asimakopoulou, D.I. Kolaitis, M.A. Founti, Geometrical characteristics of externally venting flames: assessment of fire engineering correlations using medium-scale compartment façade fire tests, J. Loss Prev. Process Ind. 44 (2016) 780-790, http://dx.doi.org/10.1016/j.jlp.2016.09.006.

[7] E. McKirdy, Huge blaze engulfs residential tower in United Arab Emirates, CNN, 〈http://edition.cnn.com/2016/03/28/middleeast/uae-ajman-tower-blaze/index.html〉, 2016.

[8] J. Hanna, A. Fantz, C.E. Sholcet, Fire engulfs downtown Dubai's high-rise Address hotel, 〈http://edition.cnn.com/2015/12/31/middleeast/dubai-address-hotel-fire/〉, 2016.

[9] N. Toscano, R. Spooner, Docklands apartment tower fire fuelled by material in building's walls, Age Vic. (2015). 〈http://www.theage.com.au/victoria/ docklands-apartment-tower-fire-fuelled-by-material-inbuildings-walls-says-mfb-20150427-1mukhx.html .

[10] E. Antonatus, Facades fire safety aspects in the context of increasing use of thermal insulation, Proceedings of the 13th Interflam Conference, Windsor U.K, 2013.

[11] C.W. Staff, Sharjah Al Baker Tower fire caused by cigarette, Construction Week Online 〈http://www.constructionweekonline.com/article-16634-sharjah-al-baker-tower-fire-caused-by-cigarette//,

2012.

[12] L. Peng, Z. Bu, X. Huang, Review on the fire safety of exterior wall claddings in high-rise buildings in China, Procedia Eng. 62 (2013) 663-670, http://dx.doi.org/10.1016/j.proeng.2013.08.112.

[13] M. Law, T. O'Brien, Fire safety of bare external structural steel, Constrado, Croydon, U.K, 1981.

[14] S. Yokoi, "Study on the prevention of fire spread caused by hot upward current", Building Research Institute, Report No 34, Tokyo, Japan, 1960.

[15] EN 1991-1-2, Eurocode 1: Actions on Structures, Part 1-2 - General Actions - Actions on Structures Exposed to Fire, European Committee for Standardization, Brussels, Belgium, 2002.

[16] C.L. Beyler, Fire plumes and ceiling jets, Fire Saf. J. 11 (1986) 53-75, http://dx. doi.org/10.1016/0379-7112(86)90052-4.

[17] K. Himoto, T. Tsuchihashi, Y. Tanaka, T. Tanaka, Modeling thermal behaviors of window flame ejected from a fire compartment, Fire Saf. J. 44 (2009) 230-240, http://dx.doi.org/10.1016/j.firesaf.2008.06.005.

[18] S. Klopovic, O.F. Turan, A comprehensive study of externally venting flames, Part I: experimental plume characteristics for through-draft and no through-draft ventilation conditions and repeatability, Fire Saf. J. 36 (2001) 99-133.

[19] S. Klopovic, O.F. Turan, A comprehensive study of externally venting flames, Part II: plume envelope and centre-line temperature comparisons, secondary fires, wind effects and smoke management system, Fire Saf. J. 36 (2001) 135-172.

[20] I. Oleszkiewicz, Fire exposure to exterior walls and flame spread on combustible cladding, Fire Technol. 26 (1990) 357-375, http://dx.doi.org/10.1007/BF01293079.

[21] Y. Lee, M.A. Delichatsios, G.W.H. Silcock, Heat flux distribution and flame shapes on the inert façade, Fire Saf. Sci. 9 (2008) 193-204, http://dx.doi.org/10.3801/IAFSS.FSS.9-193. 
[22] M.J. Hurley, SFPE Handbook of Fire Protection Engineering 5th ed, SFPE, Quincy, Massachusetts, U.S.A., 2016.

[23] D. Drysdale, An Introduction in Fire Dynamics, John Wiley, New York, U.S.A., 2011.

[24] W. Mower, Window Breakage Induced by Exterior Fires, National Institute of Standards and Technology, Gaithersburg MD, 1998.

[25] M.A. Delichatsios, Flame heights in turbulent wall fires with significant flame radiation, Combust. Sci. Technol. 39 (1984) 195-214, http://dx.doi.org/10.1080/00102208408923789.

[26] H. Morgado, J. Rodrigues, Balcony effect on the external fire spread into upper floors, J. Struct. Fire Eng. 6 (2015) 255-273.

[27] C.A. Empis, Analysis of the compartment fire parameters influencing the heat flux incident on the structural façade, (Ph.D. Thesis), University of Edinburgh, U.K., 2010.

[28] H. Huang, R. Ooka, N. Liu, L. Zhang, Z. Deng, S. Kato, Experimental study of fire growth in a reduced scale compartment under different approaching external wind conditions, Fire Saf. J. 44 (2009) 311-321.

[29] Y. Ohmiya, T. Tanaka, T. Wakamatsu, A room fire model for predicting fire spread by external flames, Fire Sci. Technol. 18 (1998) 11-21.

[30] L.G. Seigel, The projection of flames from burning buildings, Fire Technol. 5 (1969) 43-51, http://dx.doi.org/10.1007/BF02591612.

[31] C.T. Webster, M.M. Raftery, P.G. Smith, The burning of fires in rooms - Part III, FRN 474, Joint Fire Research Organization, Borehamwood, U.K, 1961.

[32] ISO 9705, International Organization for Standardization, ISO 9705 Fire Tests: Full-Scale Room Test for Surface Products, 1st Edition, Geneva, Switzerland, 1993.

[33] E.K. Asimakopoulou, K.E. Chotzoglou, D.I. Kolaitis, M.A. Founti, Characteristics of externally venting flames and their effects on the façade: a detailed experimental study, Fire Technol. 52 (2016) 2043-2069, http://dx.doi.org/10.1007/s10694-016-0575-5.

[34] D.I. Kolaitis, E.K. Asimakopoulou, M.A. Founti, A full-scale fire test to investigate the fire behaviour of the ventilated façade system, in: Proceedings of the 14th Interflam Conference, U.K, 2016.

[35] H. Yoshioka, Y. Ohmiya, M. Noak, M. Yoshida, Large-scale façade tests conducted based on ISO 13785-2 with non combustible façade specimens, Fire Sci. Technol. 31 (2012) 1-22, http://dx.doi.org/10.3210/fst.31.1.

\section{Figure captions:}

Fig. 1. Schematic of important parameters and assumed EVF shape, for NoFD (left) and FD (middle) conditions; front view of the compartment-facade configuration (right).

Fig. 2. General layout (left) and characteristic image (right) of a medium-scale façade fire test.

Fig. 3. General layout (left) and characteristic image (right) of the large-scale compartment-façade fire test.

Fig. 4. Vertical distribution of measured [38] and predicted time-averaged centreline EVF temperatures; effect of fire load (left) and opening factor (right).

Fig. 5. Vertical distribution of measured [19, 20,39] and predicted centreline EVF temperatures for test cases 5 (left) and 7 (right). 
Fig. 6. Vertical distribution of measured and predicted EVF-induced heat flux on the exposed façade surface; effect of fire load (left) and opening factor (right). 